\title{
Ultrastructure and fourier transform infrared spectrum of exopolysaccharide produced by Lactobacillus rhamnosus NBRC 3425
}

Ivy C. Emnace ${ }^{1 *}$

\begin{abstract}
Submitted: 13 June 2019 | Accepted: 24 March 2020

In the search for exopolysaccharide (EPS)-producing LAB strains as potential additive for industrial applications, EPS produced by Lactobacillus rhamnosus NBRC 3425 was subjected to partial characterization to provide further information on its structure and composition. The crude EPS was subjected to scanning electron microscopy (SEM), atomic force microscopy (AFM), transmission electron microscopy (TEM) and Fourier transform infrared spectroscopy (FTIR). Results of TEM analysis confirmed that the test organism is an EPS producer due to the presence of an unstained, clear cell wall or halo that surrounds the bacterial cell typical of a capsular EPS. SEM analysis showed that the crude EPS has pores and spaces between particles. Atomic force microscopy (AFM) at a concentration of $10 \mu \mathrm{g}$ per $\mathrm{mL}$ revealed spike-shaped lumps with an average size of $17.81 \pm 2.89 \mathrm{~nm}$. The FTIR spectrum suggested the presence of hydroxyl $(\mathrm{OH})$ groups of carbohydrate and carbonyl group $(\mathrm{C}=0)$. Results showed that based on its structural characteristics, such EPS has the potential for use as stabilizer in food products.
\end{abstract}

Keywords: atomic force microscopy, Fourier transform infrared spectroscopy, Lactobacillus rhamnosus, scanning electron microscopy, transmission electron microscopy

\section{INTRODUCTION}

The ability to produce polysaccharides is widespread among bacteria. Some bacteria can secrete polysaccharide layers on their surface, which together with a few glycoproteins, are grouped within the general term "glycocalyx". These exocellular polymers comprise the capsular polysaccharides, which form a

'Department of Food Science and Technology, Visayas State University, Baybay City, Leyte 6521-A, Philippines

*Corresponding Author. Address: Department of Food Science and Technology, Visayas State University, Baybay City, Leyte 6521-A, Philippines; Email: ivy.emnace@vsu.edu.ph DOl: $10.32945 /$ atr4219.2020 
exopolysaccharides (EPS), which form a slime layer loosely attached to the cell surface or secreted into the environment (Madigan et al 1997, Madiedo \& Gavila'n 2005).

A number of lactic acid bacteria (LAB) can produce a variety of long chain sugar polymers, called exopolysaccharides (EPS). They are synthesized either extracellularly from sucrose by glycansucrases or intracellularly by glycosyltransferases from sugar nucleotide precursors (Ganzle \& Schwab 2009, Florou-Paneri et al 2013). Most LAB-producing EPS belong to the genera Streptococcus, Lactobacillus, Lactococcus, Leuconostoc, and Pediococcus (Abbad-Andaloussi et al 1995, Roberts et al 1995, Hosono et al 1997, Florou-Paneri et al 2013).

The functional characteristics possessed by lactic acid bacteria (LAB) are responsible for their historical and modern use in food production and have been the subject of many attempts to improve their performance. Lactic acid bacteria with GRAS (Generally Regarded as Safe) status capable of expressing polysaccharides have been used for centuries and continue to generate considerable interest from the scientific and commercial communities. As a result of consumer demands for natural foods, EPS have recently been the subject of studies for their potential as natural rather than chemical stabilizers in other food products such as bakery fillings, canned foods, dry mixes, frozen foods, pourable dressings, sauces, gravies, processed cheeses, and juice drinks (Knoshaug et al 2000). Commercial additives of plant and animal origin are chemically modified to improve the rheological properties of the product and, hence, are not allowed in most European Union countries (Gibson \& Roberfroid 1995). The use of EPSproducing $L A B$ could result in a safe, natural, and healthy end product with enhanced texture and improved stability which may have an important impact on the development of novel products (German et al 1999).

Depending on the unique physico-chemical property, the microbial EPS can be used as suspension stabilizers, flocculants, encapsulating materials, emulsifiers, ion-exchange resins, molecular sieves, hosts for hydrophobic molecules, water absorbents, biosorbents of heavy metals in wastewater and natural waters, among others (Gutnick \& Bach 2000, Kachlany et al 2001).

In the search of EPS-producing LAB strains for potential industrial applications, EPS produced by $L$. rhamnosus NBRC 3425 was subjected to characterization to provide further information on its structure and composition. The crude exopolysaccharide was subjected to scanning electron microscopy, atomic force microscopy, transmission electron microscopy and Fourier transform infrared spectroscopy.

\section{MATERIALS AND METHODS}

Culture, culture medium preparation and extraction of the EPS were conducted at the Food Microbiology Laboratory of the Institute of Food Science and Technology, University of the Philippines Los Baños (UPLB). Incubation for exopolysaccharide production using environmental shaker was done at the National Institute of Molecular Biology and Biotechnology (BIOTECH), UPLB College, Laguna, Philippines. 
Ultrastructure of exopolysaccharide by Lactobacillus rhamnosus

Scanning electron microscopy (SEM) analysis of the freeze-dried EPS and transmission electron microscopy (TEM) analysis of the L. rhamnosus NBRC 3425 culture were conducted at the Research Institute for Tropical Medicine (RITM), Muntinlupa City and De La Salle University Manila, Philippines, respectively through the BIOTECH Analytical Service Laboratory, UPLB College, Laguna, Philippines. Atomic force microscopy (AFM) and Fourier transform infrared (FT-IR) spectroscopy were conducted at the UPLB Nanotechnology Laboratory and at the Chemistry and Biotechnology section of the Forest Products Research and Development Institute (FPRDI), Department of Science and Technology (DOST), College Laguna, respectively.

\section{Bacterial Strains and Culture Medium}

Lactobacillus rhamnosus NBRC 3425 strain was provided by the National Institute of Molecular Biology and Biotechnology (BIOTECH), UPLB College, Laguna, Philippines.

The stock culture was maintained in MRS broth and stored at $4^{\circ} \mathrm{C}$. The growth medium (modified SDM) (Sanchez et al 2006) (in grams per liter) consisted of Dextrose, 20 (carbon source); Tween 80, 1; ammonium citrate, 2; sodium acetate, 5; $\mathrm{MgSO}_{4} .7 \mathrm{H}_{2} \mathrm{O}, 0.1 ; \mathrm{MnSO}_{4}, 0.05 ; \mathrm{K}_{2} \mathrm{HPO}_{4}, 2$; Casamino Acid, 5 (instead of Yeast Nitrogen Base); Tryptone, 10. The initial pH of the culture medium was 6.2 prior to sterilization by heating at $121^{\circ} \mathrm{C}$ for $15 \mathrm{~min}$.

\section{Fermentation Conditions and Extraction of Crude Exopolysaccharide}

Active culture of $16 \mathrm{~h}$ Lactobacillus rhamnosus NBRC 3425 was inoculated in a sterile $50 \mathrm{~mL}$ modified Semi-Defined Medium (SDM). Each flask was inoculated with $2 \% 10^{8} \mathrm{CFU}$ per $\mathrm{mL}$ of the organism and incubated at $37^{\circ} \mathrm{C}$ for $48 \mathrm{~h}$ under shaking condition (100rpm). Extraction of the EPS was carried out by centrifugation (6000rpm for $15 \mathrm{~min}$ at $4^{\circ} \mathrm{C}$ ) and cold extraction with double volume $95 \%$ cold ethanol. Precipitation of EPS pellet was allowed to take place by incubating the solution under refrigeration condition $\left(4^{\circ} \mathrm{C}\right)$. Collected crude EPS was freeze-dried (GT2 Leybold-Heraeus, Germany) and stored in a dessicator ready for further characterization.

\section{Transmission Electron Microscopy}

Bacterial cell suspension of $L$. rhamnosus NBRC 3425 was dropped on parafilm and mounted on copper grids, 400 mesh coated with collodion. It was then blotdried with filter paper and post-stained with $1 \%$ phosphotungstic acid (PTA) for $30 \mathrm{~s}$, 1.0 and $1.5 \mathrm{~min}$. Electron microscopy was made on a TEM with an accelerating voltage of $100 \mathrm{kV}$, JEOL using a $40 \mu \mathrm{m}$ aperture.

\section{Scanning Electron Microscopy (SEM)}

Freeze-dried crude EPS was stored in a vacuum oven overnight. Then, the dried EPS was coated with gold using lon sputter JFC 1100 (JEOL). The structure of the crude exopolysaccharide was examined using a scanning electron microscope 
(SEM) JEOL-JSM 5310 with $15 \mathrm{kV}$ accelerating voltage. The microstructure was visualized at different magnifications (500x to 7500x). Whole and surface views of the EPS were taken and the morphological structure analyzed.

\section{Atomic Force Microscopy (AFM)}

Aqueous freeze-dried crude EPS solution $(10 \mu \mathrm{g}$ per $\mathrm{mL})$ was deposited to a freshly cleaved mica surface and air-dried. Atomic force microscopic images were obtained using commercial AFM (XE-70 Park System). The images were recorded under ambient conditions in a non-contact mode using micro-fabricated cantilever tips (Nano Sensor ${ }^{\mathrm{TM}}$ Pointprobe ${ }^{\circledast}$ Plus AFM Probes) with $3-5 \mu \mathrm{m}$ thickness, 22.5$37.5 \mu \mathrm{m}$ mean width, $115-135 \mu \mathrm{m}$ length and a spring constant of about $10-130 \mathrm{~nm}^{-1}$. The cantilevers have an amplitude range of $5-15 \mathrm{~nm}$. Height and deflection images were simultaneously acquired at a scan rate of $204-497 \mathrm{kHz}$. Data analysis was carried out using Park Smartscan ${ }^{\mathrm{TM}}$ AFM operating software.

\section{Analysis of Crude EPS by Fourier Transform Infrared (FT-IR)}

\section{Spectroscopy}

The crude EPS was also characterized using a Fourier transform infrared (FTIR) spectrophotometer to detect the functional groups present in the polysaccharide. Pellets for infrared analysis were obtained by grinding approximately $0.1 \mathrm{~g}$ of EPS mixed with potassium bromide $(\mathrm{KBr})$ powder. The spectra of the crude EPS as well as that of the standard were recorded using Shimadzu IR Prestige-21 Fourier Transform Infrared Spectrometer equipped with Diffuse Reflectance Accessory. The sample was subjected to IR- spectra measurement in the frequency range of 500 and $4000 \mathrm{~cm}^{-1}$.

\section{RESULTS AND DISCUSSION}

\section{Transmission Electron Microscopy (TEM) of L. rhamnosus NBRC 3425 cells}

Visualization by TEM of the L. rhamnosus NBRC 3425 cells stained with $1 \%$ phosphotungstic acid revealed a clear cell wall around the bacterial surface, as evidenced by the formation of an unstained, transparent portion around the cells confirming the formation of exopolysaccharide (Figure 1). The cross sectional area of the EPS surrounding the bacterial cell is approximately $206,136.2 \mathrm{~nm}^{2}$ with a thickness of $45.88 \mathrm{~nm}$.

Result shows that the test organism previously studied for EPS production was indeed an EPS producer. This is in congruence with the findings of various authors. Yang et al (2010) found that $L$. rhamnosus JAAS8, an isolate from Chinese sauerkraut is capable of producing two forms of EPS, a CPS (capsular polysaccharide) surrounding the bacterial surface and an SPS (slime polysaccharide) released into the culture medium, MRS broth or semi-defined medium. This strain could be potentially applied in the dairy industry to improve the physical properties of fermented milk products, ie, by increasing the water-holding 
capacity and viscosity of the products. Prior to his work, a number of LAB strains have been reported to produce both SPS and CPS. L. rhamnosus GG forms a capsule around the bacterial surface, simultaneously producing an SPS when grown in MRS broth. Lactobacillus plantarum EP56 grown in a chemically defined medium was shown to produce two EPSs, a cell-bound EPS containing glucose, galactose and $\mathrm{N}$-acetylgalactosamine at $8.5 \times 10^{5} \mathrm{Da}$, and a released EPS containing glucose, galactose and rhamnose at $4 \times 10^{4} \mathrm{Da}$ (Tallon et al 2003).

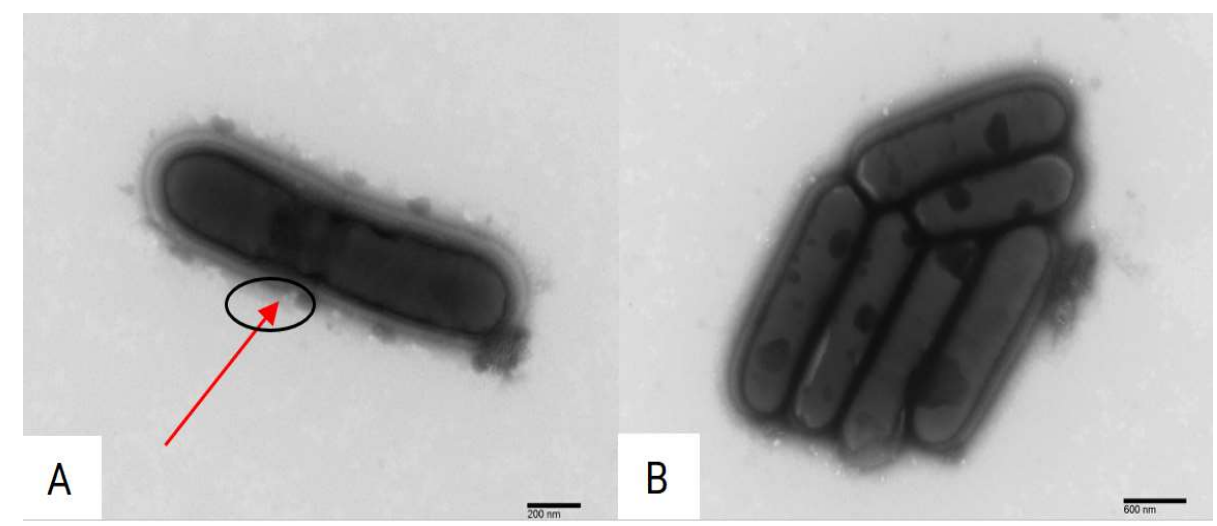

Figure 1. Transmission electron micrograph (TEM) of Lactobacillus rhamnosus NBRC 3425 cells showing formation of exopolysaccharide around the cell $(A=10000 x$ Direct Mag; $B=4000 x$ Direct Mag). Red arrow indicates the presence of capsule surrounding the cell.

\section{Scanning Electron Microscopy of the Crude EPS}

Techniques such as scanning electron microscopy (SEM) frequently provide strong evidence for the presence of exopolysaccharide, but are not capable of providing confirmatory chemical evidence (Sutherland 1990).

The SEM micrograph shown in Figures $2 \mathrm{D}$ to $2 \mathrm{~F}$ revealed that the crude EPS sample exhibits the presence of pores and spaces between particles which exist in several numbers compared to the negative control (un-inoculated medium, Figures $2 \mathrm{~A}$ to $2 \mathrm{C}$ ). The negative control exhibited a hardened and compact surface. This finding could imply that there is possible higher water absorption capacity of the isolated EPS affecting its viscosity. However, this initial finding needs further rheological study considering that the sample used was crude.

Results of this study are in agreement with the results of Kumar et al (2004) where the polymer they isolated has a porous structure with very small pores, indicating that the thin web structure of the polymer has much higher capillary forces to hold water in the gels. The small pore structure may also be responsible for the compactness of the polymer and the stability of the gel structure when subjected to external forces and the maintenance of the texture properties during storage (Mao et al 2001). Direct microscopic observations might help to understand how the relatively small amount of EPS could have such a great impact on the physical properties and water holding capacity of the polymer (Hassan et al 2003). 


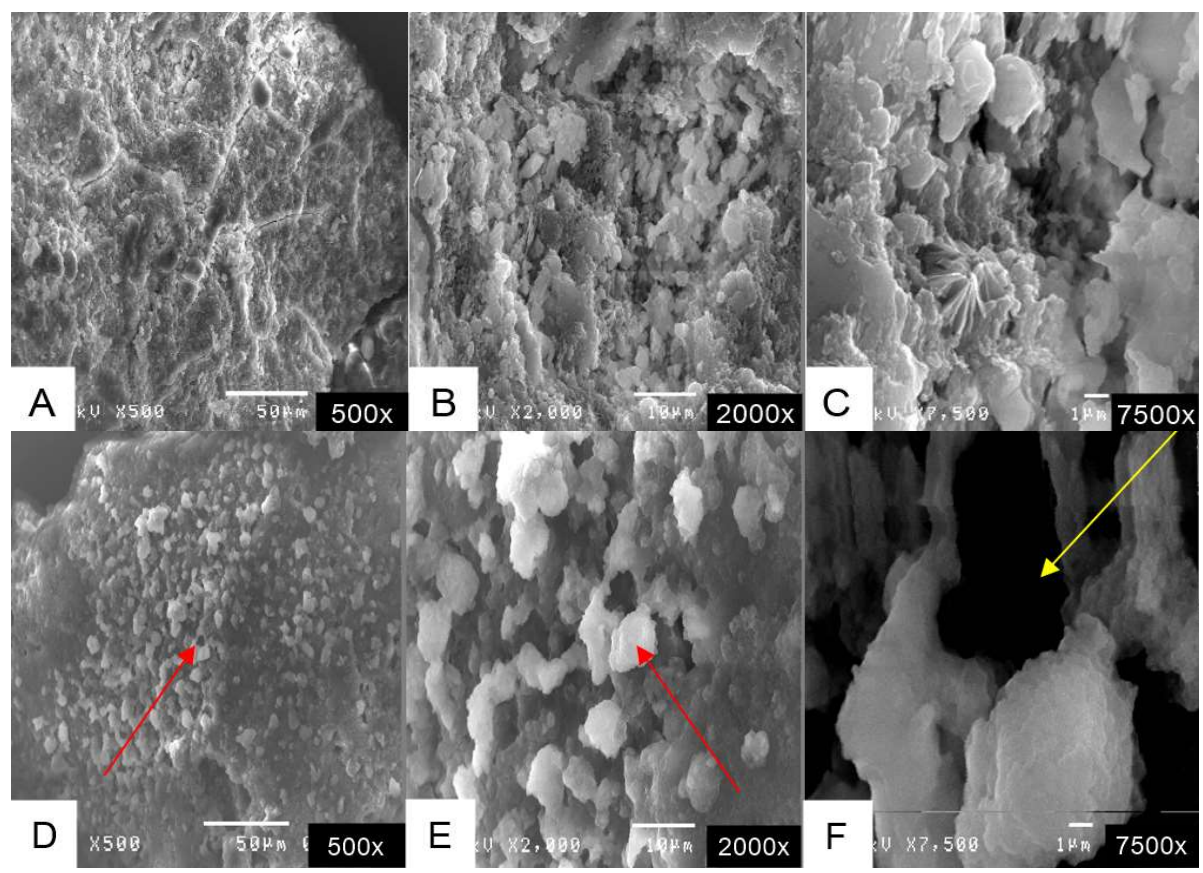

Figure 2. Scanning electron micrograph (SEM) of freeze-dried: negative control (uninoculated medium) [A (x500), B (x2000), C (x7,500)]; and crude EPS of $L$. rhamnosus NBRC 3425 incubated for 48h. [D (x500), E (x2000), F(x7,500)]. Red and yellow arrows indicate presence of EPS and cavity of EPS network, respectively.

\section{Atomic Force Microscopy (AFM) of the Crude EPS}

Atomic force microscopy (AFM) is used to determine the supramolecular structure and conformation of an EPS. It has been successfully applied to visualize a range of polysaccharides including curdlan (Ikeda \& Shishido, 2005), and oat $\beta$ glucan (Wu et al 2006). AFM was employed for the three dimensional analysis of surface structure and surface roughness of $L$. rhamnosus NBRC 3425 EPS at a concentration of $10 \mu \mathrm{g}$ per $\mathrm{mL}$. Analysis revealed spike-shaped lumps with an average size of $17.81 \pm 2.89 \mathrm{~nm}$ (Figure 3 ). According to Tao and co-workers (2008) this could be possibly formed by inter- and intra-molecular aggregation of polysaccharide.

Sajna et al (2008) reported that the surface structure seemed to be dependent on the EPS concentration. They observed that smaller lumps $3 \mathrm{~nm}$ in height and comparatively larger ones $5-6 \mathrm{~nm}$ in height at lower concentration (10 $\mu \mathrm{g}$ per $\mathrm{mL})$, whereas irregular-shaped spikes were observed at higher EPS concentration $(100 \mu \mathrm{g}$ per $\mathrm{mL})$. The surface structure of EPS from Lactobacillus species contained round lumps and chains at low concentrations and irregular lumps and chains at higher concentrations (Wang et al 2010). 


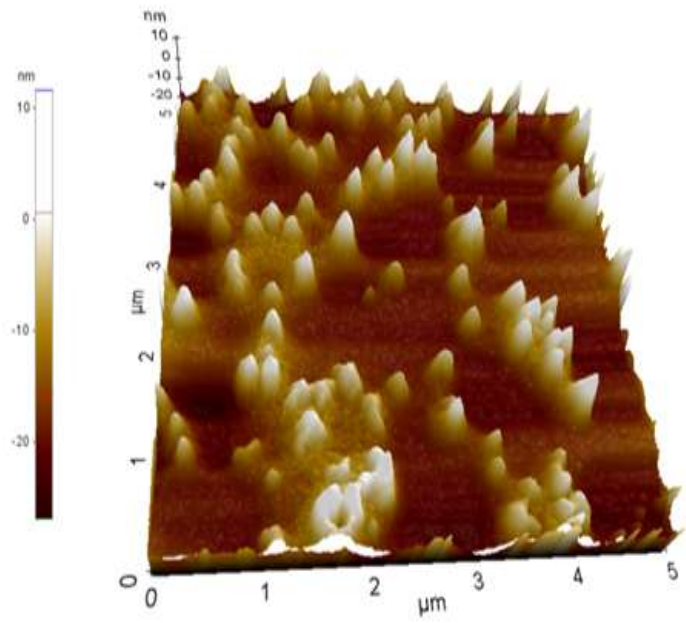

Figure 3. 3D image of $L$. rhamnosus crude exopolysaccharide at concentration $10 \mu \mathrm{g}$ per $\mathrm{mL}$ by atomic force microscopy (AFM)

\section{Fourier Transform Infrared (FT-IR) Spectroscopy}

The vibrational spectrum of a molecule is considered to be a unique physical property and is characteristic of the molecule. As such, the infrared spectrum can be used as a fingerprint for identification by the comparison of the spectrum from an "unknown" with previously recorded reference spectra (Coates 2000). FT-IR has been a potent and very useful tool for observing structural and functional group changes in exopolysaccharide (Wang et al 2008).

The FT-IR spectrum of crude EPS produced by L. rhamnosus NBRC 3425 (Figure 4) revealed major functional groups such as hydroxyl $\left(2800 \mathrm{~cm}^{-1}\right.$ to $\left.3600 \mathrm{~cm}^{-1}\right)$ and carbonyl $\left(1600 \mathrm{~cm}^{-1}\right.$ to $\left.1725 \mathrm{~cm}^{-1}\right)$ groups. The spectrum exhibited a broad stretching in the region $3184.48 \mathrm{~cm}^{-1}$ suggesting the stretching vibration of hydroxyl groups of links $(\mathrm{OH})$ indicating the presence of a polyhydroxy compound (Liu et al 2007 as cited by Paulo et al 2012). This is the characteristic absorption band of a carbohydrate ring and is responsible for the water solubility of the EPS. The presence of hydroxyl groups within the polysaccharide favors hydrogen bonding with one or more water molecules. Thus, the polymer swells and even dissolves partially or completely in water (Miller et al 1996 in Kumar et al 2004).

The absorption band appearing at 1668.3 was assigned to the stretching vibration of the carbonyl group $(\mathrm{C}=0)$. The IR spectrum of the polymer showed the presence of carboxyl groups, which may serve as binding sites for divalent cations. The carboxyl groups may also work as functional moieties to generate new and/or modified polysaccharide variants using different approaches including polymer engineering or novel formulation designing by linking this polysaccharide with starch and/or other synthesized polymers (Ha et al 1991 in Kumar et al 2004). 
Closely similar results were also obtained by Kumar et al (2011) where the EPS produced by strain $\mathrm{B} 3$ showed the presence of an $-\mathrm{OH}$ band at the $3415.31 \mathrm{~cm}^{-1}$ position and band of $\mathrm{COOH}$ groups at $1631.48 \mathrm{~cm}^{-1}$. Results further indicate the presence of other absorption bands at $1419.61-1012.63 \mathrm{~cm}^{-1}$, and $1600.92 \mathrm{~cm}^{-1}$ which is a characteristic of glucan.

This finding is best supported by the published report of Vijayabaskar et al (2011) which indicated that the IR spectrum of the crude polysaccharide sample they examined showed the band at $1000-1500 \mathrm{~cm}^{-1}$ which characterizes glucan. In addition, the spectra exhibited sharp bands around 1000, 1200, 1400, 1500 and $1600 \mathrm{~cm}^{-1}$ revealed the $(1,3)-\beta$-glucan linkages.

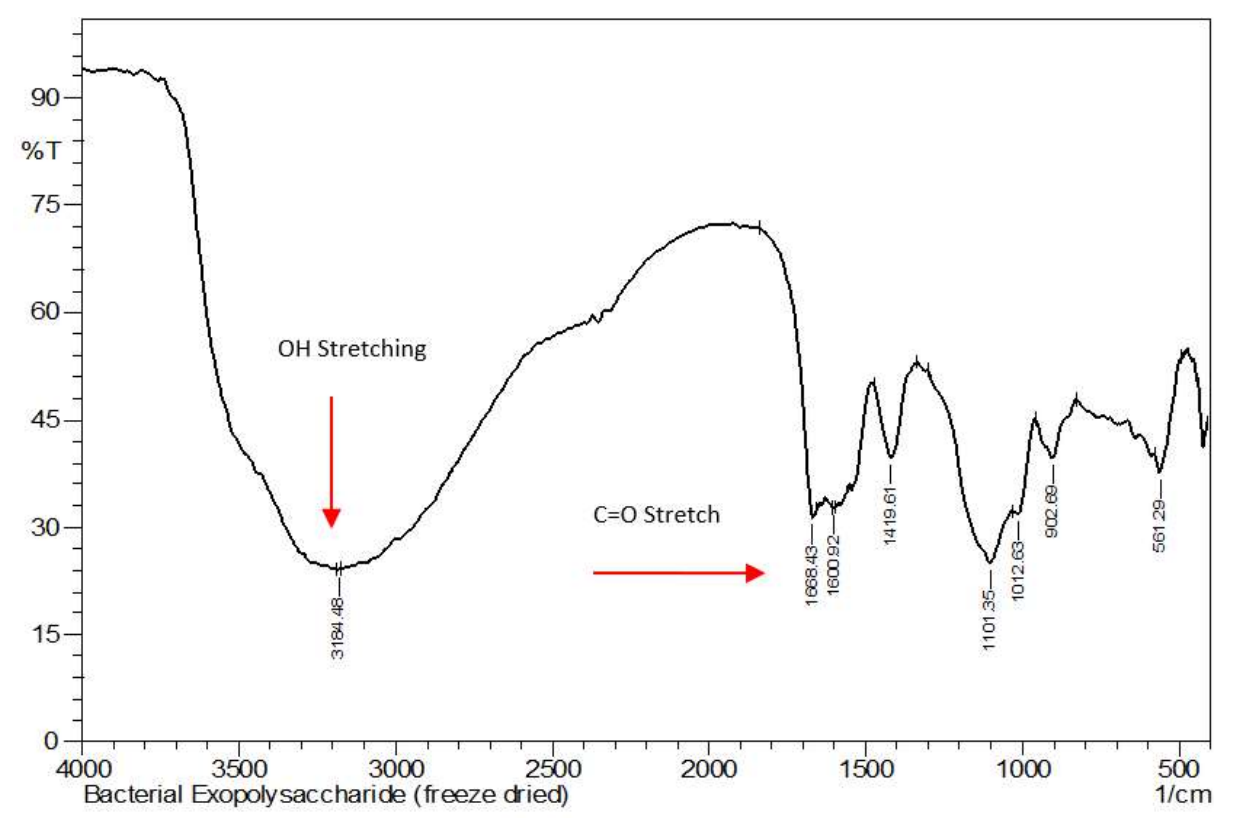

Figure 4. FT-IR spectra of freeze-dried crude exopolysaccharide produced by $L$. rhamnosus NBRC 3425

\section{CONCLUSION}

Lactobacillus rhamnosus NBRC 3425 was confirmed to be an exopolysaccharide producer due to the presence of an unstained transparent band or clear halo surrounding the bacterial cell when viewed under a transmission electron microscope. Results of this study are in agreement with the published observations of several studies on other Lactobacillus rhamnosus strains. The presence of a broad stretching in the region $3184.48 \mathrm{~cm}^{-1}$ suggesting the stretching vibration of hydroxyl groups of links $(\mathrm{OH})$ indicates the presence of a polyhydroxy compound typical of carbohydrate. The exopolysaccharide produced by L. rhamnosus NBRC 3425 showed structural characteristics that render it as a potential food stabilizer. 
Ultrastructure of exopolysaccharide by Lactobacillus rhamnosus

\section{ACKNOWLEDGMENT}

The author gratefully acknowledges the Department of Science and Technology - Science Education Institute (DOST-SEI) through ASTHRDP, UPLB consortium and Procter and Gamble, Philippines through Mr. Walter C. Emnace for the research fund of this specific study. She also thanks the Institute of Food Science and Technology and the National Institute of Molecular Biology and Biotechnology (BIOTECH), University of the Philippines (UPLB), College, Laguna for the facilities used in the research.

\section{REFERENCES}

Abbad-Andaloussi S, Talbaoui H, Marczak R \& Bonaly R. 1995. Isolation and characterization of exocellular polysaccharides produced by Bifidobacterium longum. Applied Microbiology and Biotechnology 43(6):995-1000

Coates J. 2000. Interpretation of Infrared Spectra, A Practical Approach. In Meyers RA (ed) Encyclopedia of Analytical Chemistry (pp10815-10837). John Wiley \& Sons Ltd, Chichester

Florou-Paneri P, Christaki E \& Bonos E. 2013. Chapter 25 in Lactic acid bacteria as source of functional ingredients. In Kongo JM (ed) Lactic Acid Bacteria - R \& $D$ for Food, Health and Livestock Purposes. InTechOpen

Ganzle MG and Schwab C. 2009. Ecology of exopolysaccharide formation by lactic acid bacteria: Sucrose utilisation, stress tolerance, and biofilm formation. In Ullrich M (ed) Bacterial Polysaccharides: Current Innovations and Future Trends. Caister Academic Press, Bremen, Germany

German B, Schiffrin EJ, Reniero R, Mollet B, Pfeifer A \& Neeser JR. 1999. The development of functional foods: Lessons from the gut. Trends in biotechnology 17:492-499

Gibson R and Roberfroid MB. 1995. Dietary modulation of the human colonic microbiota: Introducing the concept of prebiotics. The Journal of Nutrition 125(6):1401-1412

Gutnick DI and Bach H. 2000. Engineering bacterial biopolymers for the biosorption of heavy metals; new products and novel formulations. Applied Microbiology and Biotechnology 54:451-460

Ha YW, Stack R, Hespell RB, Gordon SH \& Bothast RJ. 1991. Some chemical and physical properties of extracellular polysaccharides produced by Butyrivibrio fibrisolvens strains. Applied and Environmental Microbiology 57:2016-2020

Hassan AN, Franka JF, EL \& Soda M. 2003. Observation of bacterial exopolysaccharide in dairy products using cryo-scanning electron microscopy. International Dairy Journal 13:755-762

Hosono A, Lee J, Ametani A, Natsume M, Hirayama M, Adachi T \& Kaminogawa S. 1997. Characterization of a water-soluble polysaccharide fraction with inmunopotentiating activity from Bifidobacterium adolescentis M101-4. Bioscience, Biotechnology and Biochemistry 61:312-316

Ikeda S and Shisido Y. 2005. Atomic force studies on heat-induced gelation of curdlan. Journal of Agricultural and Food Chemistry 53(3):786-791

Kachlany SC, Levery SB, Kim JS, Reuhs BL, Lion LW \& Andghiorse WC. 2001. Structure and carbohydrate analysis of the exopolysaccharide capsule of Pseudomonas putida G7. Environmental Microbiology 12:774-784 
Knoshaug EP, Ahlgren JA \& Trempy JE. 2000. Growth associated exopolysaccharide expression in Lactococcus lactis subspecies cremoris Ropy352. Journal of Dairy Science 83(4):633-640

Kumar MA, Anandapandian KTK \& Parthiban K. 2011. Production and characterization of exopolysaccharides (EPS) from biofilm forming marine bacterium. Brazilian Archives of Biology and Technology 54(2):259-265

Kumar CG, Joo HS, Choi JW, Koo YM \& Chang CS. 2004. Purification and characterization of an extracellular polysaccharide from haloalkalophilic Bacillus sp. I-450. Enzyme and Microbial Technology 34(7):673-681

Liu C, Lin Q, Gao Y, YE L, Xing Y \& Xi T. 2007. Characterization and antitumor activity of polysaccharide from Strongylo centrotus nudus eggs. Carbohydrate Polymers 67(3):313-318

Madiedo PR and Gavila'N CG. 2005. Invited Review: Methods for the screening, isolation, and characterization of exopolysaccharides produced by lactic acid bacteria. Journal Dairy Science 88(3):843-856

Madigan MT, Martinko JM \& Parker J. 1997. Brock Biology of Microorganisms (8th edn). Prentice Hall International Ltd., London, UK

Mao R, Tang J \& Swanson BG. 2001. Water holding capacity and microstructure of gellan gums. Carbohydrate Polymers 46:365-371

Miller JN and Whistler RL. 1996. Carbohydrates. In Fennema OR (ed) Food chemistry (3rd edn). Marcel Dekker, New York

Paulo EM, Vasconselos MP, Oliveira IS, Affe HM, De Jesus Nascimento R, de Melo IS, Roque MR \& de Assis SA. 2012. An alternative method for screening lactic acid bacteria for the production of exopolysaccharides with rapid confirmation. Food Science and Technology 32(4):710-714

Roberts CM, Fett WF, Osman SF, Wijey C, O'connor JV \& Hoover DG. 1995. Exopolysaccharide production by Bifidobacterium longum BB-79. Journal of Applied Bacteriology 78:463-468

Sajna KV, Sukumaran RK, Gottumukkala LD, Jayamurthy H, Dhar KS \& Pandey A. 2013. Studies on structural and physical characteristics of a novel exopolysaccharide from Pseudozyma sp. NII 08165. International Journal of Biological Macromolecules 59:84-89

Sanchez JI, Martinez B, Guillen G, Jimenez-Diaz R \& Rodriguez A. 2006. Culture conditions determine the balance between two different exopolysaccharides produced by Lactobacillus pentosus LPS26. Applied and Environmental Microbiology 72(12):7495-7502

Sutherland IW. 1990. Biotechnology of Microbial Exopolysaccharides. Cambridge University Press, Cambridge, United Kingdom

Tallon R, Bressollier P \& Urdaci MC. 2003. Isolation and characterization of two exopolysaccharides produced by Lactobacillus plantarum EP 56. Research in Microbiology 154(10):705-712

Tao F, Biao GZ, Yu JZ \& Ning ZH. 2008. Isolation and characterization of an acidic polysaccharide from Mesona Blumes gum. Carbohydrate Polymers 71(2): 159-169

Vijayabaskar P, Babinastarlin S, Shankar T, Sivakumar T \& Anandapandian KTK. 2011. Quantification and characterization of exopolysaccharides from Bacillus subtilis. MTCC 121. Advances in Biological Research 5(2):71-76 
Ultrastructure of exopolysaccharide by Lactobacillus rhamnosus

Wang Y, Li C, Liu P, Ahmed Z, Xiao P \& Bai X. 2010. Physical characterization of exopolysaccharide produced by Lactobacillus plantarum KF5 isolated from Tibet kefir. Carbohydrate Polymers 82(3):895-903

Wang Y, Ahmed Z, Feng W, Li C \& Song S. 2008. Physicochemical properties of exopolysaccharide produced by Lactobacillus kefiranofaciens ZW3 isolated from Tibet kefir. International Journal Biological Macromolecules 43(3):283288

Wu J, Zhang Y, Wang L, Xie B, Wang H \& Deng S. 2006. Visualization of single and aggregated hulless oat (Avena nuda L.) $(1 \rightarrow 3),(1 \rightarrow 4)-\beta$-D-glucan molecules by atomic force microscopy and confocal scanning laser microscopy. Journal of Agricultural and Food Chemistry 54(3):925-934

Yang Z, Li S, Zhang X, Zeng X, Li D, Zhao Y \& Zhang J. 2010. Capsular and slimepolysaccharide production by Lactobacillus rhamnosus JAAS8 isolated from Chinese sauerkraut: Potential application in fermented milk products. Journal of Bioscience and Bioengineering 110(1):53-57 